\title{
Encapsulation of camphor in cyclodextrin inclusion complex nanofibers via polymer-free electrospinning: enhanced water solubility, high temperature stability, and slow release of camphor
}

\author{
Asli Celebioglu ${ }^{1}$, Zeynep Aytac ${ }^{1}$, Mehmet Emin Kilic ${ }^{1}$, Engin Durgun ${ }^{1}$, and Tamer Uyar $^{1, \star}$ (I) \\ ${ }^{1}$ Institute of Materials Science and Nanotechnology, UNAM-National Nanotechnology Research Center, Bilkent University, \\ 06800 Ankara, Turkey
}

Received: 29 October 2017

Accepted: 9 December 2017

Published online:

18 December 2017

(C) Springer Science+Business

Media, LLC, part of Springer

Nature 2017

\begin{abstract}
Electrospinning of polymer-free nanofibers (NF) was successfully performed from inclusion complexes (ICs) of modified cyclodextrins [hydroxypropyl- $\beta$ cyclodextrin (HP $\beta C D)$ and hydroxypropyl- $\gamma$-cyclodextrin (HP $\gamma \mathrm{CD})]$ and camphor (HP $\beta C D /$ camphor-IC-NF and HP $\gamma \mathrm{CD} /$ camphor-IC-NF). Although camphor is a volatile and hydrophobic essential oil component, the improvement in the aqueous solubility and thermal stability of camphor by inclusion complexation with cyclodextrins was confirmed by phase solubility diagram and thermal analysis, respectively. Moreover, fast-dissolving characteristics of electrospun $\mathrm{CD} /$ camphor-IC-NF webs were also observed. Computational modeling study shows preferential orientation of camphor is variable depending on the $C D$ types. In addition, the interaction of camphor molecule is slightly stronger with $\mathrm{HP} \gamma \mathrm{CD}$ when compared to HP $\beta C D$ owing to the better allocation of guest (camphor) in host (CD) cavity originating from the better size match. Even though camphor has high volatility, significant amount of camphor was preserved in $\mathrm{HP} \beta \mathrm{CD} /$ camphor-IC-NF and $\mathrm{HP} \gamma \mathrm{CD} /$ camphor-IC-NF after electrospinning. The molar ratio of HP $\beta C D$ :camphor and HP $\gamma \mathrm{CD}$ :camphor was determined as $\sim$ 1.00:0.65 and $\sim$ 1.00:0.90 in HP $\beta C D /$ camphor-IC-NF and $\mathrm{HP} \gamma \mathrm{CD} /$ camphor-IC-NF, respectively. In short, encapsulation of camphor in cyclodextrin inclusion complex nanofibers via polymer-free electrospinning was attained, and enhanced water solubility, high temperature stability, and slow release of camphor were achieved for CD/camphor-IC-NF.
\end{abstract}

Address correspondence to E-mail: tamer@unam.bilkent.edu.tr 


\section{Introduction}

Essential oils are widely used in medical, food, and cosmetic industry due to their unique characteristics such as being as antibacterial, antioxidant, antifungal, antiseptic, and fragrance compounds [1]. Since essential oils are mixtures of hydrophobic volatile aroma compounds, their processing is often problematic due to their highly volatile nature and their low water solubility. Thus, various encapsulation strategies are often applied to increase the efficiency and long-term shelf life of essential oils [2]. Having the advantage of being a room temperature process, electrospinning is becoming one of the promising encapsulation method, wherein variety of bioactive agents such as drugs, plant extracts, essential oils, flavors/fragrances, and food additives are encapsulated in the electrospun nanofiber matrix for possible applications in pharmaceuticals and foods [3, 4]. Electrospinning is a very practical technique in order to obtain nanofibers and nanofibrous materials from wide range of materials including polymers, blends, composites, etc. [3, 5]. Nanofibers/nanowebs produced via electrospinning possess unique properties including high surface-to-volume ratio and

(a)

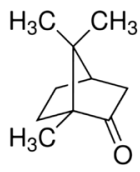

(b)
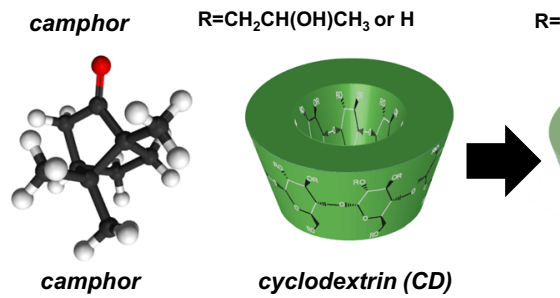

(c)

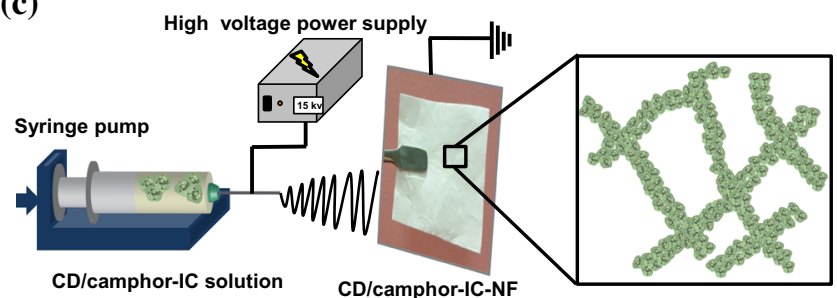

Figure 1 a Chemical structure of camphor, $\mathrm{HP} \beta C D$, and $\mathrm{HP} \gamma \mathrm{CD}$ b schematic representation $\mathrm{CD} /$ camphor-IC formation and $\mathbf{c}$ electrospinning of $\mathrm{CD} /$ camphor-IC solution to produce $\mathrm{CD} /$ camphorIC nanofibers (CD/camphor-IC-NF), representative SEM images nanoporous structure along with design flexibility and functionalization with additives $[3,5]$.

Cyclodextrins (CDs) (Fig. 1a, b) are cyclic oligosaccharides, which are well known by their noncovalent inclusion complexes with various compounds [6]. The native types of CDs are named as $\alpha$ $\mathrm{CD}, \beta-\mathrm{CD}$, and $\gamma$-CD having 6,7 , and $8 \alpha$-D-glucopyranoside units in their cyclic structure, respectively. Chemically modified CDs (i.e., hydroxypropyl-, methyl-, carboxymethyl-CDs) are of importance in terms of their high water solubility when compared to native CDs $[7,8]$. CDs are used as molecular encapsulation agents since they can form inclusion complexes with variety of hydrophobic compounds (drugs, essential oils, organic compounds, food and cosmetic additives, etc.) [6-8]. The cyclodextrin inclusion complexation facilitates the high thermal stability for volatile compounds and enhances the water solubility of the hydrophobic guest molecules [6-8].

In general, electrospinning involves polymeric solutions in which active agents like food additives, drugs, etc., can be incorporated into polymeric nanofibrous matrix [3, 4]. Nevertheless, we have shown that electrospun polymeric nanofibrous
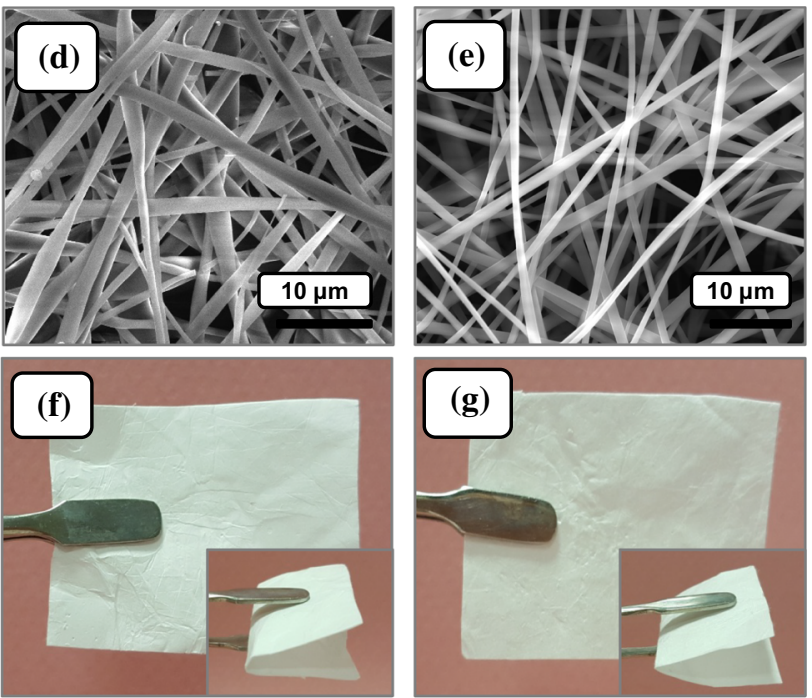

of electrospun nanofibers of $\mathbf{d} \mathrm{HP} \beta \mathrm{CD} /$ camphor-IC-NF and e $\mathrm{HP} \gamma \mathrm{CD} /$ camphor-IC-NF; the photographs of nanofibrous webs of $\mathbf{f} \mathrm{HP} \beta \mathrm{CD} /$ camphor-IC-NF and $\mathbf{g} \mathrm{HP} \gamma \mathrm{CD} /$ camphor-IC-NF. 
matrices are sometimes not very effective to preserve the volatile additives [9-12]. Therefore, in our recent studies, cyclodextrin inclusion complexes (CD-ICs) of many volatile/hydrophobic compounds were incorporated into electrospun polymeric nanofibers previously to overcome the volatility and stability problems associated with these active agents [9-12]. As an alternative approach to CD-IC-incorporated electrospun polymeric nanofibers, electrospinning of polymer-free nanofibers from CD-IC systems was also achieved by our group [13-20]. We have observed that the high aqueous solubility of modified CDs enables to obtain nanofibers from highly concentrated CD solutions [21, 22]. Therefore, CD-IC [13-20] solutions ultimately result in the formation of nanofibers due to the self-assembly and aggregation of CDs in their highly concentrated solutions.

Camphor (1,7,7-trimethyl-bicyclo[2.2.1]hepta-2-one) (Fig. 1a) is a white crystalline and natural compound, which is widely used in numerous industrial and pharmaceutical applications as a fragrance, food additive, and antidepressant, anti-inflammatory [23]. Camphor has a very low water solubility; moreover, camphor has a limited stability because it is a highly volatile compound having a rapid sublimation nature. Hence, the encapsulation of camphor is of great significance for its applications by preservation of its therapeutic efficacy. In this study, we achieved the encapsulation of camphor in cyclodextrin inclusion complex nanofibers via polymer-free electrospinning. That is, inclusion complexes of camphor with two different types of modified CDs [hydroxypropyl- $\beta$ cyclodextrin (HPßCD) and hydroxypropyl- $\gamma-\mathrm{cy}-$ clodextrin $(\mathrm{HP} \gamma \mathrm{CD})]$ were electrospun into nanofibers ( $\mathrm{HP} \beta \mathrm{CD} /$ camphor-IC-NF and $\mathrm{HP} \gamma \mathrm{CD} /$ camphor-IC-NF) as free-standing nanofibrous webs without using any polymeric fiber matrix (Fig. 1c). Enhanced water solubility, high temperature stability, and slow release of camphor were successfully achieved for these CD/camphor-IC-NF nanofibrous webs.

\section{Materials and methods}

\section{Materials}

Camphor ( $\geq 95 \%$, Sigma-Aldrich, Germany), deuterated dimethylsulfoxide (DMSO-d6, deuteration degree $\min 99.8 \%$ for NMR spectroscopy, Merck,
Germany), potassium bromide (KBr, 99\%, FTIR grade, Sigma-Aldrich), hydroxypropyl-beta-cyclodextrin $(\mathrm{HP} \beta C \mathrm{CD}$, degree of substitution: $\sim 0.6$, Cavasol ${ }^{\circledR}$ W7 HP Pharma, kindly donated by Wacker Chemie (Germany)), and hydroxypropyl-gamma-cyclodextrin $(\mathrm{HP} \gamma \mathrm{CD}$, degree of substitution: 0.6, Cavasol ${ }^{\circledR}$ W8 HP Pharma, kindly donated by Wacker Chemie) were used as-received. The water was distilled/deionized from a Millipore Milli-Q ultrapure water system.

\section{Preparation of solutions for electrospinning}

$\mathrm{CD} /$ camphor-IC solutions were prepared in aqueous solution $(0.5 \mathrm{~mL})$ by using two types of modified CD (HP $\beta C D$ and HP $\gamma C D)(0.8 \mathrm{~g})$ and camphor $(0.083$ and $0.075 \mathrm{~g}$ ) at 1:1 molar ratio. First, camphor powder was dispersed in water, then CDs $[160 \%(\mathrm{w} / \mathrm{v})]$ was added to the dispersions, and the resulting solutions were stirred at room temperature (RT) for $12 \mathrm{~h}$. $\mathrm{CD} /$ camphor-IC solutions were turbid in the beginning; however, clear and homogenous solutions were achieved later on after the dissolution of camphor in the presence of $C D$ in the aqueous solution. Finally, electrospinning was performed in order to produce nanofibers of $\mathrm{HP} \beta \mathrm{CD} /$ camphor-IC-NF and $\mathrm{HP} \gamma \mathrm{CD} /$ camphor-IC-NF in the form of self-standing nanofibrous webs. The composition, viscosity, and conductivity of $\mathrm{CD} /$ camphor-IC solutions and morphological characteristics of $\mathrm{CD} /$ camphor-IC nanofibers (CD/camphor-IC-NF) along with average fiber diameter (AFD) are summarized in Table 1. Pristine CD nanofibers without camphor (HPßCD-NF and $\mathrm{HP} \gamma \mathrm{CD}-\mathrm{NF}$ ) were also produced as control samples according to our previous reports by electrospinning of aqueous $\mathrm{HP} \beta \mathrm{CD}$ and $\mathrm{HP} \gamma \mathrm{CD}$ solutions having $160 \%(\mathrm{w} / \mathrm{v})$ concentration $[21,22]$.

\section{Electrospinning of nanofibers}

$\mathrm{CD} /$ camphor-IC solutions in $1 \mathrm{~mL}$ plastic syringe (metallic needle having $0.4 \mathrm{~mm}$ inner diameter) were mounted on a syringe pump (KD Scientific, KDS-101, USA) and pumped at $0.5 \mathrm{~mL} / \mathrm{h}$ rate toward a grounded metal collector covered with aluminum foil. The distance between the needle and the collector was $10-15 \mathrm{~cm}$, and electric field $(15-20 \mathrm{kV})$ was applied by using a high voltage power supply (AU Series, Matsusada Precision Inc., Japan). The electrospinning was performed in a horizontal setup in a 
Table 1 Properties of the CD/camphor-IC solutions used for electrospinning and morphological characteristics of the resulting $\mathrm{CD} /$ camphor-IC nanofibers

\begin{tabular}{|c|c|c|c|c|c|c|}
\hline Solutions & $\% \mathrm{CD}^{\mathrm{a}}(\mathrm{w} / \mathrm{v})$ & $\begin{array}{l}\text { \% camphor } \\
(\mathrm{w} / \mathrm{w})\end{array}$ & Viscosity $(\mathrm{Pa} \cdot \mathrm{s})$ & $\begin{array}{l}\text { Conductivity } \\
(\mu \mathrm{S} / \mathrm{cm})\end{array}$ & $\begin{array}{l}\text { Average fiber } \\
\text { diameter (nm) }\end{array}$ & Fiber morphology \\
\hline $\mathrm{HP} \beta \mathrm{CD} /$ camphor-IC & 160 & 9.4 & 0.52 & 15.29 & $1330 \pm 440$ & Bead-free nanofibers \\
\hline $\mathrm{HP} \gamma \mathrm{CD} /$ camphor-IC & 160 & 8.4 & 0.37 & 7.95 & $1110 \pm 305$ & Bead-free nanofibers \\
\hline
\end{tabular}

${ }^{\mathrm{a}}$ With respect to solvent (water)

${ }^{\mathrm{b}}$ With respect to total weight of the sample

Plexiglas box at $25{ }^{\circ} \mathrm{C}$ and $18 \%$ relative humidity. After electrospinning, the electrospun $\mathrm{CD} /$ camphorIC-NF (HP $\beta C D /$ camphor-IC-NF and $\mathrm{HP} \gamma \mathrm{CD} / \mathrm{cam}$ phor-IC-NF) webs and pure CD-NF (HP $\beta C D-N F$ and $\mathrm{HP} \gamma \mathrm{CD}-\mathrm{NF})$ webs were kept in refrigerator $\left(+4{ }^{\circ} \mathrm{C}\right)$ prior to their analyses.

\section{Measurements and characterization}

Phase solubility test was performed according to the method of Higuchi and Connors [24]. An excess amount of camphor was added to aqueous CD (HP $\beta C D$ and $H P \gamma C D$ ) solutions, and the suspensions were shaken at RT. After equilibrium was achieved at the end of $48 \mathrm{~h}$, the suspensions were filtered with $0.45 \mu \mathrm{m}$ membrane filter. The absorption of the solutions was determined at $286 \mathrm{~nm}$ by UV spectroscopy (Varian, Cary 100). The absorption values were converted into the concentration of camphor by the solubility of camphor without CDs [25]. The experiments were carried out in triplicate, and the results were reported as average \pm standard deviation.

The stability constant $\left(K_{C}\right)$ was calculated based on the phase solubility diagram according to the following equation:

$K_{\mathrm{C}}=$ slope $/ S_{0}(1-$ slope $)$,

where $S_{0}$ is the intrinsic solubility of camphor in the absence of CDs.

The viscosity and conductivity of $\mathrm{HP} \beta \mathrm{CD} /$ camphor-IC and $\mathrm{HP} \gamma \mathrm{CD} /$ camphor-IC solutions were measured at RT via Anton Paar Physica MCR 301 Rheometer equipped with a cone/plate accessory (spindle type CP 40-2) at a constant shear rate of $100 \mathrm{~s}^{-1}$ and Inolab $^{\circledR} \quad \mathrm{pH} /$ Cond $720-\mathrm{WTW}$, respectively.
Scanning electron microscopy (SEM, FEI-Quanta 200 FEG) was used to examine the morphology of electrospun $\mathrm{HP} \beta \mathrm{CD} /$ camphor-IC-NF and $\mathrm{HP} \gamma \mathrm{CD} /$ camphor-IC-NF webs. Nanofibrous web samples were placed on metal stubs using double-sided copper tape and sputtered with $5 \mathrm{~nm}$ of $\mathrm{Au} / \mathrm{Pd}$ (PECS682) to minimize the charging during SEM imaging. AFD of the fibers was calculated directly from SEM images by measuring the diameter of about 100 fibers.

Five milliliters of water was added to camphor (powder), $\mathrm{HP} \beta \mathrm{CD} /$ camphor-IC-NF, and $\mathrm{HP} \gamma \mathrm{CD} /$ camphor-IC-NF in petri dishes, and video (Supporting Video 1) was recorded for camphor and $\mathrm{CD} /$ camphor-IC-NF samples in order to show the water-solubility character of each sample.

$20 \mathrm{mg} / \mathrm{mL}$ of each HP $\beta C D /$ camphor-IC-NF and $\mathrm{HP} \gamma \mathrm{CD} /$ camphor-IC-NF was dissolved in d6-DMSO, and proton nuclear magnetic resonance $\left({ }^{1} \mathrm{H}-\mathrm{NMR}\right)$ spectra were recorded at $400 \mathrm{MHz}$ (Bruker DPX-400). Then, the characteristic chemical shifts $(\delta)$ given in parts per million (ppm) corresponding to $C D$ and camphor were determined, and the integrations were calculated via Mestrenova software. Finally, the molar ratio of $\mathrm{CD}$ and camphor in each $\mathrm{CD} / \mathrm{cam}$ phor-IC-NF was determined by the proportion of the peak belonging to $\mathrm{CD}$ and camphor.

Thermal properties of camphor, HP $\beta C D-N F$, $\mathrm{HP} \beta \mathrm{CD}$ /camphor-IC-NF, HP $\gamma \mathrm{CD}-\mathrm{NF}$, and $\mathrm{HP} \gamma \mathrm{CD} /$ camphor-IC-NF were investigated by thermogravimetric analysis (TGA, TA Q500) under nitrogen atmosphere by heating the nanofibrous webs starting from $25{ }^{\circ} \mathrm{C}$ at the heating rate of $20{ }^{\circ} \mathrm{C} / \mathrm{min}$.

Differential scanning calorimetry (DSC, TA Q2000) analyses were performed for camphor, HP $\beta C D-N F$, $\mathrm{HP} \gamma \mathrm{CD}-\mathrm{NF}$, HP $\beta \mathrm{CD} /$ camphor-IC-NF, and HP $\gamma \mathrm{CD}$ / 
camphor-IC-NF at a heating rate of $20^{\circ} \mathrm{C} / \mathrm{min}$ from 40 to $200{ }^{\circ} \mathrm{C}$ under nitrogen flow.

X-ray diffraction (XRD) (PANalytical X'Pert powder diffractometer) was used to examine the crystalline structure of camphor, HP $\beta C D-N F, H P \gamma C D-$ $\mathrm{NF}, \mathrm{HP} \beta \mathrm{CD} /$ camphor-IC-NF, and $\mathrm{HP} \gamma \mathrm{CD} / \mathrm{cam}-$ phor-IC-NF at a range of $2 \theta=5^{\circ}-30^{\circ}$ using $\mathrm{Cu} \mathrm{K \alpha}$ radiation in powder diffraction configuration.

The infrared spectra of camphor, HP $\beta C D-N F$, $\mathrm{HP} \gamma \mathrm{CD}-\mathrm{NF}, \mathrm{HP} \beta \mathrm{CD} /$ camphor-IC-NF, and HP $\gamma \mathrm{CD} /$ camphor-IC-NF were recorded by Fourier transform infrared spectrometer (FTIR, Bruker-VERTEX 70). The samples were prepared as pellets by mixing them with potassium bromide $(\mathrm{KBr})$ for the measurement. The scans (64 scans) were recorded between 4000 and $400 \mathrm{~cm}^{-1}$ at the resolution of $4 \mathrm{~cm}^{-1}$.

The amount of camphor released from $\mathrm{HP} \beta \mathrm{CD} /$ camphor-IC-NF and $\mathrm{HP} \gamma \mathrm{CD} /$ camphor-ICNF was measured using headspace gas chromatography-mass spectrometry (HS GC-MS) for $4 \mathrm{~h}$ at two different temperatures $\left(37\right.$ and $75{ }^{\circ} \mathrm{C}$ ). The Agilent Technologies 7890A gas chromatograph coupled with an Agilent Technologies 5975C inert MSD combined with a triple-axis detector was used. The capillary column was HP-5MS (Hewlett-Packard, Avondale, PA) $(30 \mathrm{~m} \times 0.25 \mathrm{~mm}$ i.d., $0.25 \mu \mathrm{m}$ film thickness). Ten milligrams of nanofibrous webs was put in a $20-\mathrm{mL}$ headspace glass vial. The vials with the samples were agitated at $500 \mathrm{rpm}$. The syringe temperature was kept at 37 and $75^{\circ} \mathrm{C}$. Injection volume taken from the vials was $250 \mu \mathrm{L}$ of vapor to the HS GC-MS by using a headspace injector. The oven temperature was programmed as follows: initial $40{ }^{\circ} \mathrm{C}$ (held for $0.5 \mathrm{~min}$ at $40{ }^{\circ} \mathrm{C}$ ), increased from 40 to $110^{\circ} \mathrm{C}$ at a rate of $5^{\circ} \mathrm{C} / \mathrm{min}$ (held for $1 \mathrm{~min}$ at $\left.110^{\circ} \mathrm{C}\right)$. HS GC-MS was operated in a splitless and selected ion monitoring mode (SIM). NIST MS Search 2.0 library was used to identify the camphor peaks. The release experiments were performed in triplicate, and the results are reported as average \pm standard deviation.

\section{Computational method}

We performed first-principles calculations based on density functional theory $[26,27]$ by using Vienna ab initio Simulation Package (VASP) [28, 29]. The exchange-correlation interaction is approximated by generalized gradient approximation (GGA-PBE) [30], and the semiempirical dispersion potential is utilized to describe the van der Waals interactions [31]. The projector augmented-wave (PAW) potentials with kinetic energy cutoff $520 \mathrm{eV}$ are used [32, 33]. This methodology is applied to optimize the positions of the atoms by setting convergence criteria on the total energy and force to $10^{-4} \mathrm{eV}$ and $10^{-2} \mathrm{eV} / \AA$, respectively. The effect of solvent is modeled by considering implicit solvation model where continuum dielectric description is used [34].

\section{Results and discussion}

\section{Phase solubility studies}

Phase solubility diagrams of $\mathrm{HP} \beta \mathrm{CD} / \mathrm{camphor}$ and $\mathrm{HP} \gamma \mathrm{CD} /$ camphor systems obtained in aqueous solution are shown in Fig. 2. The solubility of camphor increased linearly with the increasing amount of $\mathrm{CD}$ for both of the systems, and these diagrams are classified as $A_{\mathrm{L}}$ type. In addition, the linear improvement in the solubility of camphor confirms the presence of 1:1 complex $[35,36]$. Such that, in the study of Tanaka et al. [37], it was observed that the solubility of camphor increased linearly as a function of concentration with HP $\beta C D$ and $\mathrm{HP} \gamma \mathrm{CD}$. Therefore, it was concluded that the molar ratio of these complexes is $1: 1$ and the type of the diagram is $A_{\mathrm{L}}$. In addition, the stability constant $\left(K_{\mathrm{C}}\right)$ of $\mathrm{HP} \beta \mathrm{CD} / \mathrm{cam}$ phor-IC and $\mathrm{HP} \gamma \mathrm{CD} /$ camphor-IC calculated from the Eq. 1 was 229 and $251 \mathrm{M}^{-1}$, respectively. As it is observed, $\mathrm{HP} \gamma \mathrm{CD}$ can form relatively more stable complexes with camphor molecules compared to $\mathrm{HP} \beta \mathrm{CD}$.

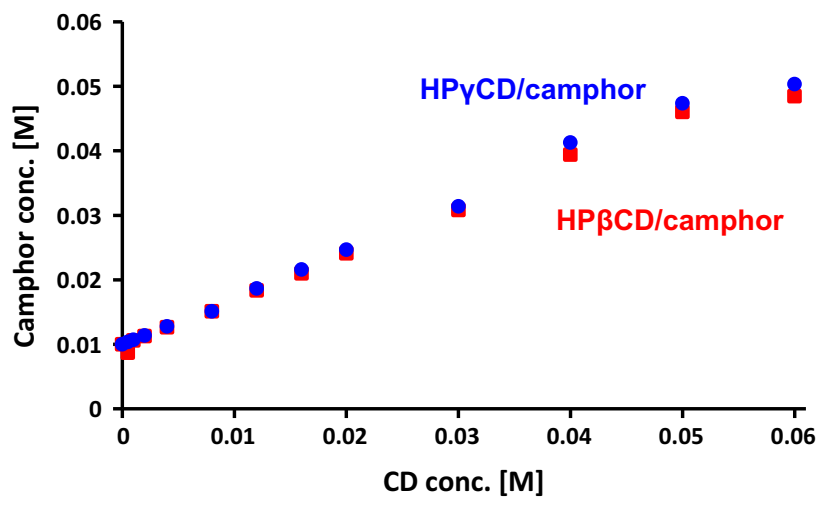

Figure 2 Phase solubility diagram of $\mathrm{HP} \beta \mathrm{CD} /$ camphor and $\mathrm{HP} \gamma \mathrm{CD} /$ camphor systems in water $(n=3)$. 
In the earlier reports, different types of CDs were employed to obtain $\mathrm{CD} /$ camphor-ICs in powder form [37, 38]. In the study of Ciobanu et al. [38], stability constant and complexation efficiency of complexes formed between camphor and $\alpha-C D, \beta-$ $\mathrm{CD}, \gamma-\mathrm{CD}$, hydroxypropyl- $\beta$-cyclodextrin (HP $\beta C D$ ), randomly methylated- $\beta$-cyclodextrin (RAMEB), and of a low methylated- $\beta$-cyclodextrin (CRYSMEB) and it was concluded that the stability constant was in the order of $\beta$-CD $>$ CRYSMEB $>$ HP $\beta C D>$ RAMEB $>$ $\gamma-\mathrm{CD}>\alpha$-CD. Tanaka et al. [37] produced inclusion complex of camphor with HPaCD, HP $\beta C D$, and $\mathrm{HP} \gamma \mathrm{CD}$. It was reported that HP $\beta C D$ significantly increased the solubility of camphor, and 1:1 stability constant of HP $\beta C D$ complexes was higher than that of other types of CDs. In addition, release rate of camphor was decreased by complexation with CDs, and rate of decrease was in agreement with the stability constant between $\mathrm{CD}$ and camphor. However, in case of our study, we have obtained relatively more stable complexation for HP $\gamma$ CD-based system compared to HP $\beta C D$, and it will be discussed in the following sections.

\section{Computational modeling of CD/camphor-IC}

In this study, the interaction of camphor molecule with $\mathrm{HP} \beta C \mathrm{CD}$ and $\mathrm{HP} \gamma \mathrm{CD}$ was analyzed by using ab initio modeling techniques. Firstly, all the structures are relaxed in vacuum and then water without any constraint to obtain the optimized lowest energy configurations. Next, considering the center of mass of $\mathrm{CD}$ as origin, camphor molecule is approached to both of the $\mathrm{CD}$ through wider rim with different orientations. The four possible orientations of camphor and the variation of interaction energy are shown in Fig. 3a-d. The interaction energy $\left(E_{\text {int }}\right)$ for 1:1 stoichiometry is defined as:

$E_{\text {int }}=E_{\mathrm{T}}(\mathrm{CD})+E_{\mathrm{T}}($ camphor $)-E_{\mathrm{T}}(\mathrm{IC})$,

where $E_{\mathrm{T}}(\mathrm{CD}), E_{\mathrm{T}}$ (camphor), and $E_{\mathrm{T}}(\mathrm{IC})$ are the total energy of CD (HP $\beta C D$ or HP $\gamma C D)$, camphor, and their ICs (HP $\beta C D /$ camphor-IC and $\mathrm{HP} \gamma \mathrm{CD} / \mathrm{cam}$ phor-IC), respectively. Total energies are calculated both in vacuum and in solvent (water). Positive $E_{\text {int }}$ indicates an attractive interaction between $C D$ and camphor. The variation of $E_{\text {int }}$ shows that there is no energy barrier for formation of IC indicating an exothermic reaction. For HP $\beta C D$, camphor stays at wider rim and starts to deform HP tails when pushed inside. For $\mathrm{HP} \gamma \mathrm{CD}$, "dc" orientation of camphor where carbonyl group is close to the narrow rim is favored, whereas " $a b$ " orientation is favored in case of HP $\beta C D$. Kokkinout et al. [39] reported the results concerning computational modeling of enantiomers of camphor with $\alpha-C D$ dimer, and one disordered camphor molecule is observed to occupy three major sites. Thus, carbonyl group of camphor pointing toward the primary rim of $\mathrm{CD}$ or carbonyl group is located on the $\mathrm{CD}$ dimer interface. We also obtain from our modeling results that " $\mathrm{dc}$ " orientation is one of the favorable orientations correlated with the literature.

According to the described computational model, IC is presumed to be formed when $E_{\text {int }}$ is maximized which is at 3 and $-1 \AA$ for HP $\beta C D$ and HP $\gamma C D$, respectively. The ground state configurations for $\mathrm{HP} \beta \mathrm{CD} /$ camphor and $\mathrm{HP} \gamma \mathrm{CD} /$ camphor are shown in Fig. 3. At this point, $E_{\text {int }}$ is defined as the complexation energy $\left(E_{\text {comp }}\right)$ for 1:1 stoichiometry. $E_{\text {comp }}$ is calculated as 22.78 and $23.63 \mathrm{kcal} / \mathrm{mol}$ for $\mathrm{HP} \beta \mathrm{CD} /$ camphor-IC and $\mathrm{HP} \gamma \mathrm{CD} /$ camphor-IC, respectively. Positive $E_{\text {comp }}$ indicates that formation of IC is energetically favored between CD (HP $\beta C D$ and $\mathrm{HP} \gamma \mathrm{CD}$ ) and camphor. We also checked the possibility of complex formation for 2:1 stoichiometry. While HP $\beta C D /$ camphor-IC is not formed in 2:1 stoichiometry due to size mismatch, $\mathrm{HP} \gamma \mathrm{CD} / \mathrm{cam}$ phor-IC is plausible. However, $E_{\text {comp }}$ decreases for the second camphor molecule and becomes $11.02 \mathrm{kcal} / \mathrm{mol}$. Therefore, it can be concluded from all these results that $\mathrm{HP} \gamma \mathrm{CD}$ tends to form slightly more stable complexes with camphor, compared to $\mathrm{HP} \beta C D$ due to a more favorable allocation of camphor in $\mathrm{HP} \gamma \mathrm{CD}$ cavity.

The calculations are repeated in water for 1:1 stoichiometry to include the effect of solvent, and similar trends are obtained. However, upon interaction with water, $E_{\text {comp }}$ decreases for both cases and becomes 16.54 and $16.99 \mathrm{kcal} / \mathrm{mol}$ for $\mathrm{HP} \beta C D /$ camphor-IC and $\mathrm{HP} \gamma \mathrm{CD} /$ camphor-IC, respectively. The decrease in $E_{\text {comp }}$ can be attributed to hydrophobic nature of $\mathrm{CD}$ cavity and camphor (because of the large hydrocarbon content). After revealing the interaction between CDs and camphor molecule, we analyzed the solubility of IC. The solubility of camphor in water is low $\left(1.2 \mathrm{~g} \mathrm{dm}^{-3}\right)$ but it can be enhanced by complex formation with CDs. However, the solubility cannot be estimated directly from our model, yet, 

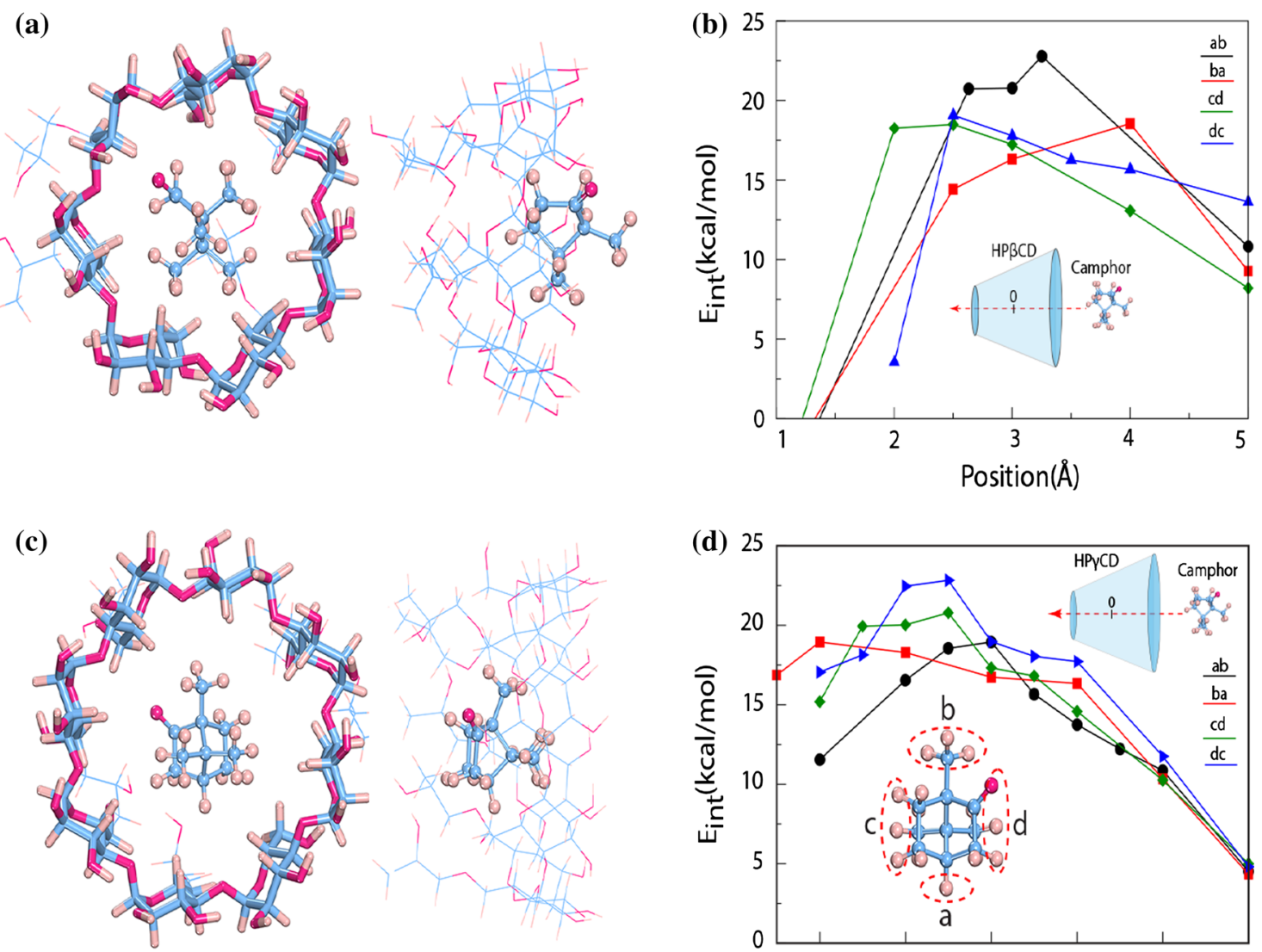

Figure 3 a Top and side view of $\mathrm{HP} \beta C D /$ camphor-IC for $1: 1$ stoichiometry with "ab" orientation, $\mathbf{b}$ the variation of interaction energy of HP $\beta C D$ and camphor with distance, $\mathbf{c}$ top and side view of $\mathrm{HP} \gamma \mathrm{CD}$ /camphor-IC for 1:1 stoichiometry with " $\mathrm{dc}$ "

solvation energy can be calculated which reveals the trend. Solvation energy $\left(E_{\text {solv }}\right)$ is defined as:

$E_{\text {solv }}=E_{\mathrm{T}}(\mathrm{IC})_{\text {water }}-E_{\mathrm{T}}(\mathrm{IC})_{\text {vacuum }}$,

where $E_{\mathrm{T}}(\mathrm{IC})_{\text {water }}$ and $E_{\mathrm{T}}(\mathrm{IC})_{\text {vacuum }}$ are the total energy of $\mathrm{HP} \beta \mathrm{CD} /$ camphor-IC and $\mathrm{HP} \gamma \mathrm{CD} /$ camphor-IC in water and vacuum, respectively. $E_{\text {solv }}$ of camphor molecule is calculated as $-3.79 \mathrm{kcal} / \mathrm{mol}$ confirming the low solubility in water. On the other hand, $E_{\text {solv }}$ is -70.71 and $-81.29 \mathrm{kcal} / \mathrm{mol}$ for $\mathrm{HP} \beta \mathrm{CD} /$ camphor-IC and $\mathrm{HP} \gamma \mathrm{CD} /$ camphor-IC, suggesting a substantial increase in solubility of the CDIC system in water upon complexation.

\section{Morphology analysis of nanofibers}

The representative SEM images of HP $\beta C D$ /camphorIC-NF and $\mathrm{HP} \gamma \mathrm{CD} /$ camphor-IC-NF are given in Fig. 1d-g. As confirmed from the SEM images, bead-

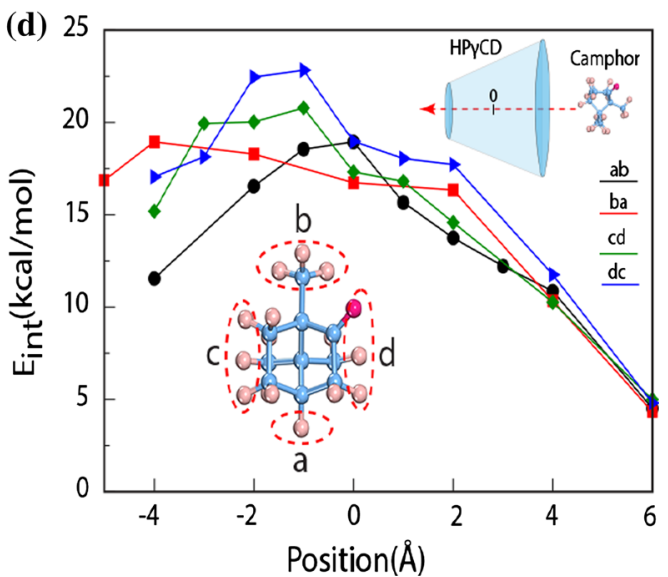

orientation, and $\mathbf{d}$ the variation of interaction energy of $\mathrm{HP} \gamma \mathrm{CD}$ and camphor with distance. The possible orientations of camphor are shown as inset. Blue, purple, and light pink balls represent carbon, oxygen, and hydrogen atoms, respectively.

free and uniform nanofibers were successfully electrospun from these $\mathrm{CD} /$ camphor-IC aqueous systems having such high concentrated solution (i.e., $160 \%, \mathrm{w} / \mathrm{v})$. The use of such high concentration of $\mathrm{CDs}$ for the electrospinning of uniform nanofibers from pure CD [21, 22, 40, 41] systems and CD-IC [13-20] systems was optimized from our previous studies. It is worth mentioning that in this study, we have performed polymer-free electrospinning in which $\mathrm{CD} /$ camphor-IC aqueous systems are being electrospun without using a carrier polymeric matrix. Typically, high molecular weight polymers and high polymer concentrations are desirable for the electrospinning of nanofibers since polymer chain entanglements and overlapping are quite crucial for uniform fiber formation [42, 43]. For the electrospinning of small molecules such as CDs without using a carrier polymeric matrix, in our earlier studies 
[13-22, 40, 41] we found out that highly concentrated solutions of CDs are required since self-aggregation of these supramolecular CD molecules helps the electrospinning of uniform fibers without the break of the jet.

Average fiber diameter (AFD) of $\mathrm{HP} \beta \mathrm{CD} / \mathrm{cam}$ phor-IC-NF and $\mathrm{HP} \gamma \mathrm{CD}$ /camphor-IC-NF was calculated as $1330 \pm 440$ and $1110 \pm 305 \mathrm{~nm}$, respectively. The slight difference in AFD of nanofibers could be due to the viscosity and conductivity differences between $\mathrm{HP} \beta \mathrm{CD} /$ camphor-IC and $\mathrm{HP} \gamma \mathrm{CD} / \mathrm{cam}-$ phor-IC solutions (Table 1). In electrospinning, solutions having less viscosity and high conductivity yield thinner fibers due to the more stretching of the jet [43]. Here, both the viscosity and conductivity values of $\mathrm{HP} \gamma \mathrm{CD} /$ camphor-IC solution are lower than $\mathrm{HP} \beta C D /$ camphor-IC solution (Table 1). It appears that $\mathrm{HP} \gamma \mathrm{CD} /$ camphor-IC-NF has slightly thinner AFD than HP $\beta C D /$ camphor-IC-NF possibly due to the low viscosity of the $\mathrm{HP} \gamma \mathrm{CD} /$ camphor-IC solution. After electrospinning of $\mathrm{CD} /$ camphor-IC systems, self-standing and flexible nanofibrous webs of $\mathrm{HP} \beta \mathrm{CD} /$ camphor-IC-NF and $\mathrm{HP} \gamma \mathrm{CD} /$ camphorIC-NF were obtained as depicted in Fig. 1f, g. Even though the electrospun nanofibers are made of nonpolymeric $\mathrm{CD} /$ camphor-IC systems, both $\mathrm{HP} \beta \mathrm{CD} /$ camphor-IC-NF and HP $\gamma \mathrm{CD} /$ camphor-IC$\mathrm{NF}$ nanofibrous webs have shown flexible character (Fig. 1f, g). Moreover, we have shown that these $\mathrm{CD} /$ camphor-IC-NF nanofibrous webs are readily soluble in water. Here, solubility tests were done by pouring $5 \mathrm{~mL}$ of water on camphor, $\mathrm{HP} \beta \mathrm{CD} / \mathrm{cam}-$ phor-IC-NF, and $\mathrm{HP} \gamma \mathrm{CD} /$ camphor-IC-NF (Supporting Video 1). Camphor could not be dissolved in water, and on the other hand, the CD/camphor-ICNF nanofibrous webs were dissolved within $2 \mathrm{~s}$ and $\mathrm{CD}$ makes the camphor soluble in water, as also confirmed by the phase solubility tests (Fig. 2).

\section{The molar ratio of $\mathrm{CD} /$ camphor-IC}

The presence and the molar ratio of camphor in the electrospun CD/camphor-IC-NF samples were confirmed by proton nuclear magnetic resonance $\left({ }^{1} \mathrm{H}\right.$ NMR). The ${ }^{1} \mathrm{H}-\mathrm{NMR}$ spectra of HP $\beta \mathrm{CD} /$ camphor-IC$\mathrm{NF}$ and $\mathrm{HP} \gamma \mathrm{CD} /$ camphor-IC-NF dissolved in $d 6-$ DMSO are presented in Fig. $4 \mathrm{a}, \mathrm{b}$. The initial molar ratio of $\mathrm{HP} \beta C D$ :camphor and $\mathrm{HP} \gamma \mathrm{CD}$ :camphor was prepared as 1:1 prior to electrospinning of $\mathrm{CD} / \mathrm{cam}$ phor-IC aqueous solutions. After electrospinning, the
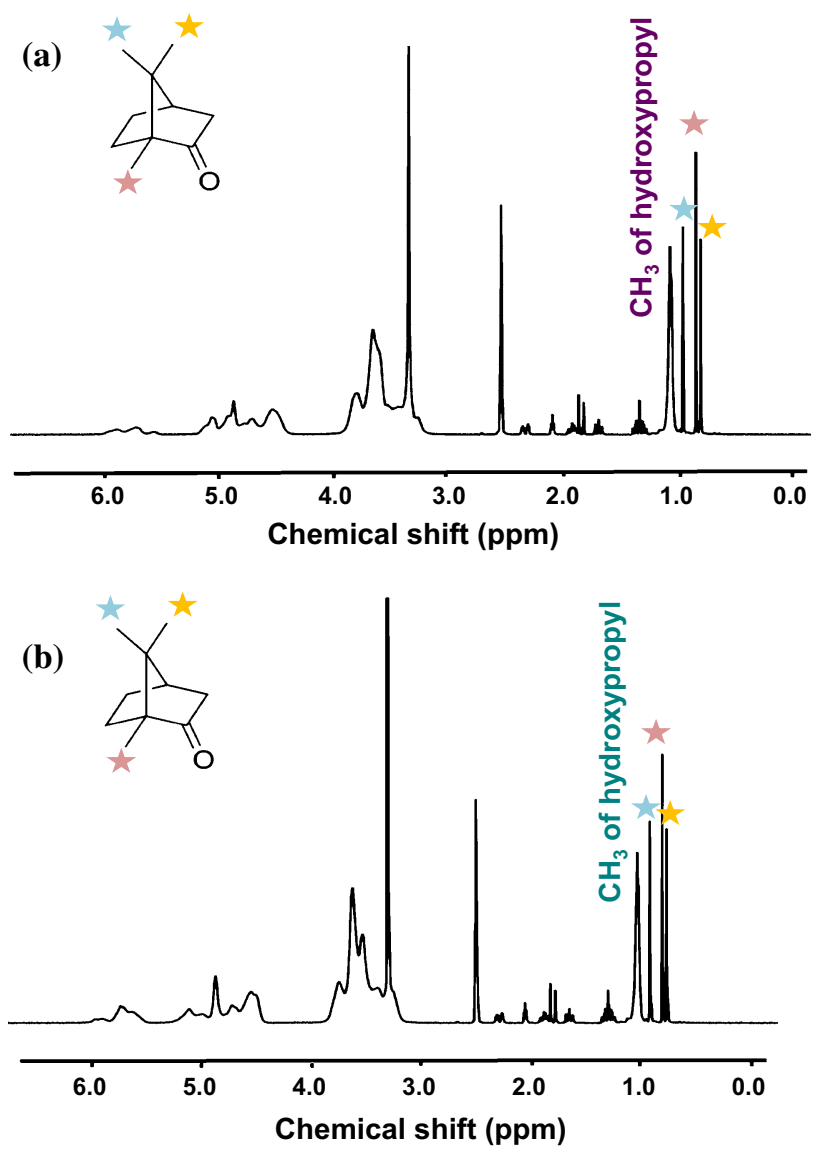

Figure $4{ }^{1} \mathrm{H}-\mathrm{NMR}$ spectra of a $\mathrm{HP} \beta C D /$ camphor-IC-NF and b $\mathrm{HP} \gamma \mathrm{CD} /$ camphor-IC-NF dissolved in $d 6$-DMSO.

molar ratio of HP $\beta C D$ :camphor and $\mathrm{HP} \gamma \mathrm{CD}$ :camphor in $\mathrm{HP} \beta \mathrm{CD} /$ camphor-IC-NF and $\mathrm{HP} \gamma \mathrm{CD} /$ camphorIC-NF was determined as $\sim 1.00: 0.65$ and $\sim$ 1.00:0.90, respectively. For molar ratio calculation from ${ }^{1} \mathrm{H}-\mathrm{NMR}$ spectrum, the proportion of the peaks belonging to $\mathrm{CD}$ and camphor at 1 and $0.9 \mathrm{ppm}$, respectively, were taken into account. The ${ }^{1} \mathrm{H}-\mathrm{NMR}$ studies revealed that $\sim 65$ and $\sim 90 \%$ of the initial amount of camphor were preserved in $\mathrm{HP} \beta \mathrm{CD} /$ camphor-IC-NF and $\mathrm{HP} \gamma \mathrm{CD} /$ camphor-IC$\mathrm{NF}$, respectively. Although camphor is a volatile compound, substantial amount of camphor was preserved after electrospinning in the $\mathrm{CD} /$ camphorIC-NF samples owing to the inclusion complexation between camphor and CD (HP $\beta C D$ and $\mathrm{HP} \gamma \mathrm{CD})$ in the fiber matrix. It was also noticed that $\mathrm{HP} \gamma \mathrm{CD} /$ camphor-IC-NF has preserved higher amount of camphor when compared to $\mathrm{HP} \beta \mathrm{CD} /$ camphor-IC-NF. This is probably originated from the higher complexation efficiency of $\mathrm{HP} \gamma \mathrm{CD}$ with camphor due to wider cavity of $\mathrm{HP} \gamma \mathrm{CD}$ which 
provides a better localization and specific interaction for camphor when compared to HPßCD, which was also indicated by the modeling and phase solubility results.

\section{Thermal analysis of nanofibers}

Camphor has a volatile nature; therefore, it is of importance for camphor molecules to be protected from evaporation. Here, thermal stability of camphor in $\mathrm{HP} \beta \mathrm{CD} /$ camphor-IC-NF and $\mathrm{HP} \gamma \mathrm{CD} /$ camphorIC-NF samples was investigated by TGA (Fig. 5). Thermal evaporation of pure camphor starts at around $40^{\circ} \mathrm{C}$ and completely evaporated below $150{ }^{\circ} \mathrm{C}$. In order to better analyze the TGA data of $\mathrm{CD} /$ camphor-IC-NF samples, the thermal behavior of electrospun pure CD nanofibers (HP $\beta C D-N F$ and
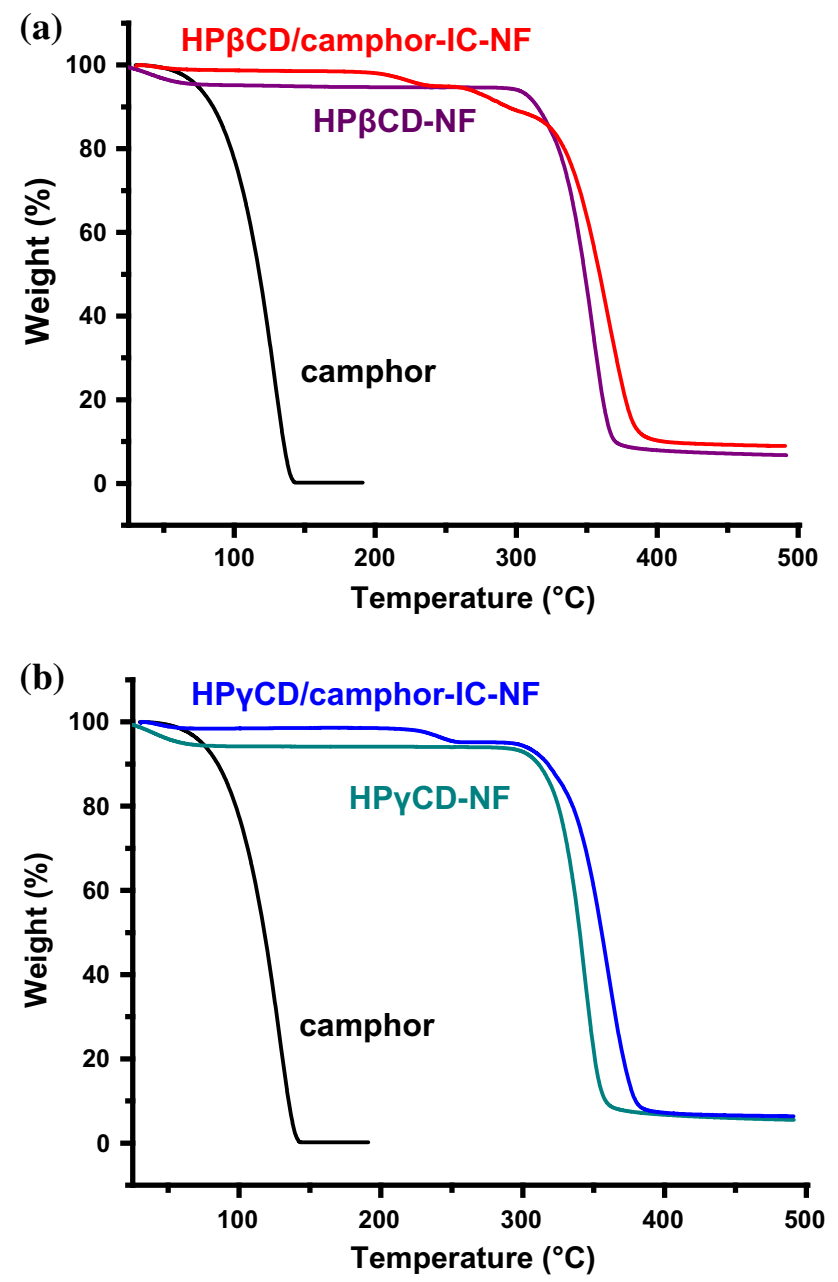

Figure 5 TGA thermograms of a camphor, HP $\beta C D-N F$, $\mathrm{HP} \beta \mathrm{CD} /$ camphor-IC-NF and $\mathbf{b}$ camphor, HP $\gamma \mathrm{CD}-\mathrm{NF}$, $\mathrm{HP} \gamma \mathrm{CD}$ /camphor-IC-NF.
$\mathrm{HP} \gamma \mathrm{CD}-\mathrm{NF})$ was also examined for comparison. Both pure HP $\beta C D-N F$ and HP $\gamma$ CD-NF exhibited two steps of weight loss below $100{ }^{\circ} \mathrm{C}$ and between 275 and $400{ }^{\circ} \mathrm{C}$ corresponding to water loss and main thermal degradation of $C D$, respectively. The water in $\mathrm{HP} \beta \mathrm{CD}-\mathrm{NF}$ and $\mathrm{HP} \gamma \mathrm{CD}-\mathrm{NF}$ was also calculated as $\sim 4.80$ and $\sim 5.75 \%$ from the water loss of each CD type. The TGA data reveal that thermal stability of camphor was improved by inclusion complexation for both HP $\beta C D /$ camphor-IC-NF and $\mathrm{HP} \gamma \mathrm{CD} / \mathrm{cam}$ phor-IC-NF (Fig. 5a, b). Four stages of weight loss observed for $\mathrm{HP} \beta \mathrm{CD} /$ camphor-IC-NF: below 100, 180-250, 250-300, and $300-415^{\circ} \mathrm{C}$, which was attributed to the water loss, evaporation of camphor in two steps, and main degradation of $\mathrm{HP} \beta C D$, respectively. For $\mathrm{HP} \gamma \mathrm{CD} /$ camphor-IC-NF sample, the first weight loss below $100{ }^{\circ} \mathrm{C}$ was related to the water loss, the second weight loss at around $195-260{ }^{\circ} \mathrm{C}$ is due to the thermal evaporation of camphor, and the third weight loss between 325 and $400{ }^{\circ} \mathrm{C}$ is the thermal degradation of $\mathrm{HP} \gamma \mathrm{CD}$. In brief, when compared to pure camphor, the thermal evaporation of camphor has shifted to much higher temperature (above $200{ }^{\circ} \mathrm{C}$ ) in CD/camphor-IC-NF samples, which is due to the inclusion complexation between camphor and $\mathrm{CD}$ in the nanofiber matrix. So, the thermal stability enhancement of camphor has been successfully achieved by encapsulation of camphor in electrospun polymer-free CD-IC nanofiber matrix. In addition, the amount of water in HP $\beta C D /$ camphor-IC-NF and $\mathrm{HP} \gamma \mathrm{CD} /$ camphor-IC-NF was calculated to be $\sim 1.15$ and $\sim 1.50 \%$, which are lower than the amount of water present in HP $\beta C D-N F$ and $H P \gamma C D-N F$. Since the water in the cavity of $\mathrm{HP} \beta C D$ and $\mathrm{HP} \gamma \mathrm{CD}$ was replaced with camphor during complex formation. This result is another support for complexation of camphor with $\mathrm{HP} \beta C \mathrm{CD}$ and $\mathrm{HP} \gamma \mathrm{CD}$.

Figure 6a represents DSC thermograms of camphor, HP $\beta C D-N F, H P \gamma C D-N F, H P \beta C D /$ camphor-IC$\mathrm{NF}$, and $\mathrm{HP} \gamma \mathrm{CD} /$ camphor-IC-NF. Camphor exhibited an endothermic peak at around $175^{\circ} \mathrm{C}$ that corresponds to its melting point, whereas the melting point of camphor was not observed in $\mathrm{HP} \beta \mathrm{CD} /$ camphor-IC-NF and HP $\gamma \mathrm{CD} /$ camphor-ICNF. The disappearance of thermal transitions such as melting point $[12,44]$ or glass transition [19] of guest molecules in the presence of CDs is well known, which is used to confirm the formation of inclusion complexes between CDs and guest molecules. Hence, the absence of melting point of camphor in 

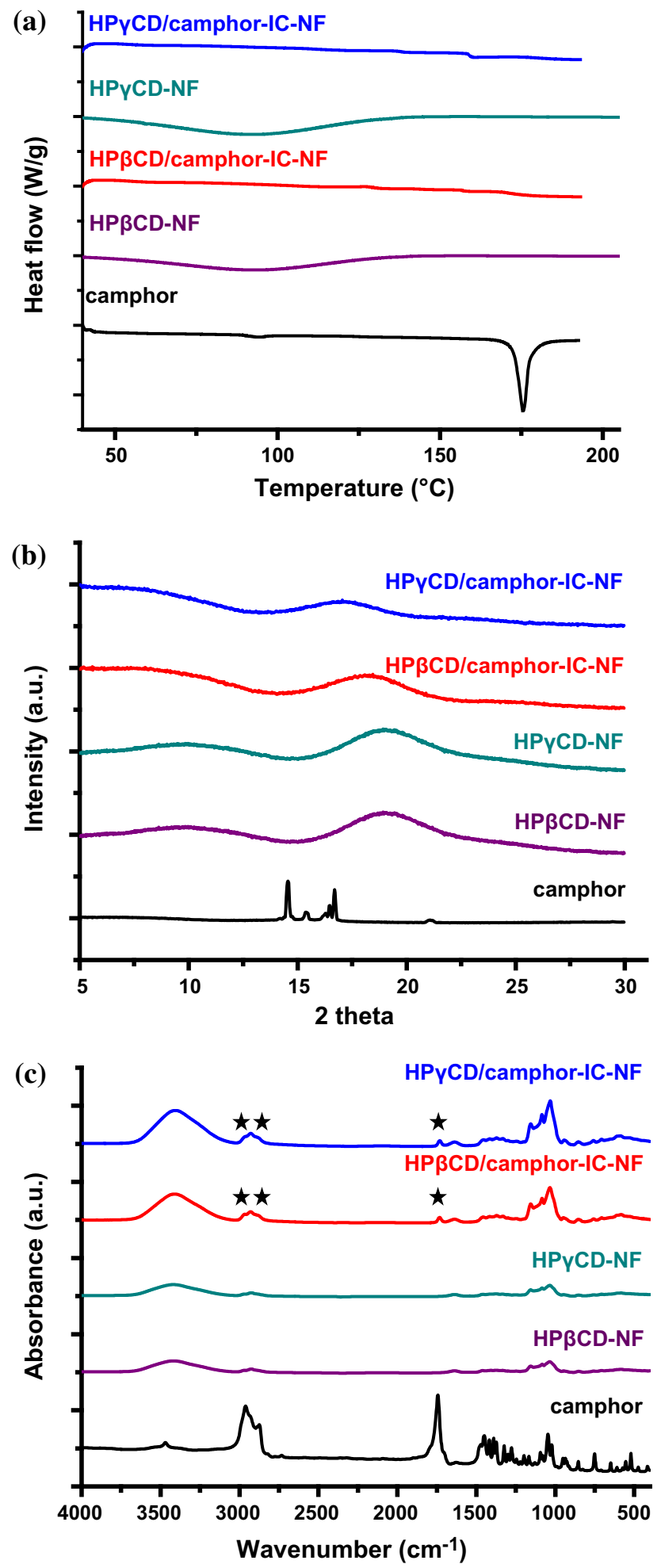

Figure 6 a DSC thermograms of camphor, HP $\beta C D-N F$, $\mathrm{HP} \beta \mathrm{CD}$ /camphor-IC-NF, HP $\gamma \mathrm{CD}-\mathrm{NF}$, and $\mathrm{HP} \gamma \mathrm{CD} /$ camphor-ICNF; b XRD patterns of camphor, HP $\beta C D-N F$, HP $\gamma C D-N F$, $\mathrm{HP} \beta C D$ /camphor-IC-NF, and HP $\gamma \mathrm{CD} /$ camphor-IC-NF, c FTIR spectra of camphor, HP $\beta C D-N F, H P \gamma C D-N F, H P \beta C D /$ camphorIC-NF, and $\mathrm{HP} \gamma \mathrm{CD} /$ camphor-IC-NF.
$\mathrm{CD} /$ camphor-IC-NFs further confirms the inclusion complexation state of camphor within CD cavity in this nanofiber matrix. The dehydration of CDs in HP $\beta C D-N F$ and HP $\gamma$ CD-NF is observed as typical broad endothermic peaks between 25 and 160 and $25-155{ }^{\circ} \mathrm{C}$, respectively. However, $\mathrm{HP} \beta \mathrm{CD} /$ camphorIC-NF and $\mathrm{HP} \gamma \mathrm{CD} /$ camphor-IC-NF did not exhibit any dehydration peak, which is a support for camphor to be included in the cavity of CDs by replacing the water in the cavity. HP $\beta C D /$ camphor-IC-NF and $\mathrm{HP} \gamma \mathrm{CD} /$ camphor-IC-NF have only low amount of water as confirmed by TGA results.

\section{Structural characterization of nanofibers}

The XRD studies were performed for camphor, HP $\beta C D-N F, H P \gamma C D-N F, H P \beta C D /$ camphor-IC-NF, and $\mathrm{HP} \gamma \mathrm{CD} /$ camphor-IC-NF, and the resulting diffraction patterns are displayed in Fig. 6b. Camphor is a crystalline molecule with sharp diffraction peaks at $14.5^{\circ}, 15.4^{\circ}, 16.5^{\circ}$, and $16.7^{\circ}$, whereas HP $\beta C D-N F$ and HP $\gamma$ CD-NF exhibited amorphous pattern. Characteristic crystalline peaks of camphor disappeared in the diffraction pattern of $\mathrm{HP} \beta \mathrm{CD} /$ camphor-IC-NF and HP $\gamma \mathrm{CD} /$ camphor-ICNF. This result is the proof inclusion complexation between camphor and $C D$, suggesting that camphor molecules are included inside the CD cavity and they are separated from each other by $C D$ molecules where camphor molecules cannot form crystals. Hence, the absence of a camphor diffraction peak in $\mathrm{CD} /$ camphor-IC-NF samples strongly suggests that camphor is encapsulated as an inclusion complex within the CD nanofiber matrix after electrospinning.

FTIR analyses were also performed for camphor, HP $\beta C D-N F, H P \gamma C D-N F, H P \beta C D /$ camphor-IC-NF, and $\mathrm{HP} \gamma \mathrm{CD} /$ camphor-IC-NF (Fig. 6c). The characteristic absorption peaks of pure CDs were observed at around 1030, 1080, and $1157 \mathrm{~cm}^{-1}$ due to the coupled $\mathrm{C}-\mathrm{C}$ and $\mathrm{C}-\mathrm{O}$ stretching vibrations and antisymmetric stretching vibration of the $\mathrm{C}-\mathrm{O}-\mathrm{C}$ glycosidic bridge; 1638,2925 , and $3401 \mathrm{~cm}^{-1}$ corresponding to $\mathrm{H}-\mathrm{OH}$ bending, $\mathrm{C}-\mathrm{H}$ stretching, and $\mathrm{O}-$ $\mathrm{H}$ stretching, respectively $[15,17]$. The characteristic absorption peaks of camphor are observed at around 3466, 2961, 2870, 1739, 1624, 1476, 1445, 1387, 1245, 1153, 1126, and $1095 \mathrm{~cm}^{-1}$ [45]. Most of the camphor peaks overlap in the $1500-1000 \mathrm{~cm}^{-1}$ range with the characteristic peaks of CDs, which makes it difficult to analyze the FTIR spectra of HPßCD/camphor-IC- 
$\mathrm{NF}$ and $\mathrm{HP} \gamma \mathrm{CD} /$ camphor-IC-NF in this range. Nonetheless, the camphor peaks at around 2960 and $2871 \mathrm{~cm}^{-1}$ also exist in the FTIR spectra of $\mathrm{HP} \beta \mathrm{CD} /$ camphor-IC-NF and HP $\gamma \mathrm{CD} /$ camphor-ICNF. However, due to the interaction between camphor and CDs, camphor peaks shifted to 2964 and $2879 \mathrm{~cm}^{-1}$ for HPßCD/camphor-IC-NF and 2963 and $2875 \mathrm{~cm}^{-1}$ for $\mathrm{HP} \gamma \mathrm{CD} /$ camphor-IC-NF. But, the higher intensity of the camphor peaks (2960 and $2871 \mathrm{~cm}^{-1}$ ) in the spectra of HP $\beta C D /$ camphor-IC-NF and $\mathrm{HP} \gamma \mathrm{CD} /$ camphor-IC-NF as compared to pure CD-NF samples confirms the presence of camphor in these $\mathrm{CD} /$ camphor-IC-NF samples. In addition, the salient peak of camphor at $1740 \mathrm{~cm}^{-1}$ is obviously seen in the FTIR spectra of $\mathrm{HP} \beta \mathrm{CD} /$ camphor-IC-NF and $\mathrm{HP} \gamma \mathrm{CD} /$ camphor-IC-NF at $1742 \mathrm{~cm}^{-1}$, and this further confirms the existence of camphor in the $\mathrm{CD} /$ camphor-IC-NF samples. In addition, shifting of this peak from 1740 to $1742 \mathrm{~cm}^{-1}$ shows the presence of an interaction between camphor and CDs, which further suggests the inclusion complex formation.

\section{Release study}

The release of camphor from $\mathrm{HP} \beta \mathrm{CD} /$ camphor-IC$\mathrm{NF}$ and $\mathrm{HP} \gamma \mathrm{CD} /$ camphor-IC-NF was measured at 37 and $75{ }^{\circ} \mathrm{C}$, and the results are given in Fig. 7. The release of camphor increased as the temperature

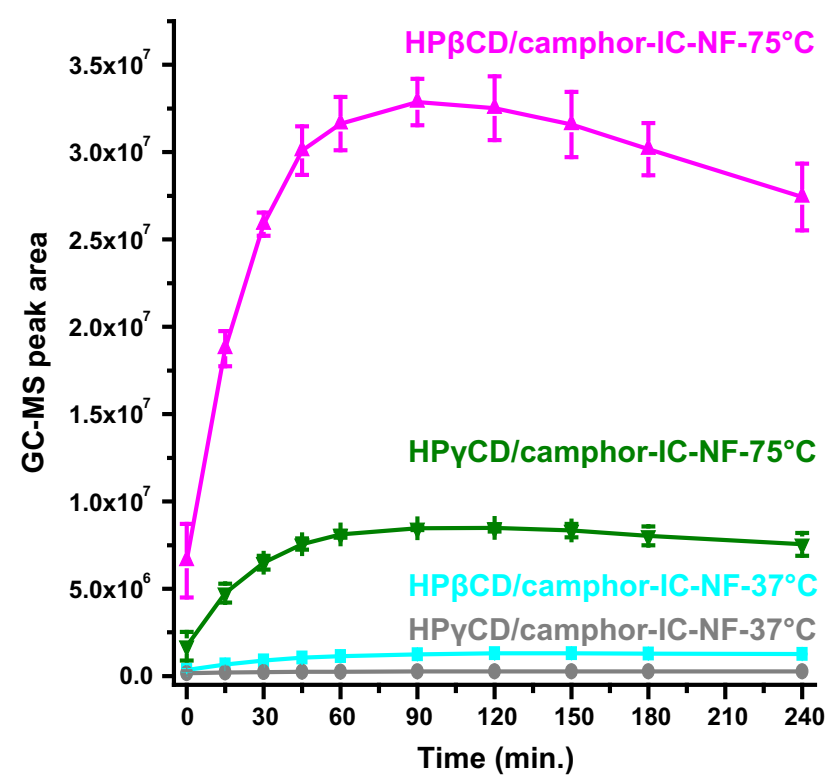

Figure 7 Cumulative release of camphor from $\mathrm{HP} \beta \mathrm{CD} /$ camphorIC-NF and $\mathrm{HP} \gamma \mathrm{CD} /$ camphor-IC-NF at 37 and $75^{\circ} \mathrm{C}(n=3)$. The error bars in the figure represent the standard deviation. increased from 37 and $75{ }^{\circ} \mathrm{C}$ in both $\mathrm{HP \beta CD} /$ camphor-IC-NF and $\mathrm{HP} \gamma \mathrm{CD} /$ camphor-IC-NF owing to the diffusion coefficient increment of the camphor molecules [46]. The preserved amount of camphor is calculated less from ${ }^{1} \mathrm{H}-\mathrm{NMR}$ in $\mathrm{HP} \beta \mathrm{CD} /$ camphorIC-NF, but the total released amount of camphor is much more both at 37 and $75{ }^{\circ} \mathrm{C}$ as compared to $\mathrm{HP} \gamma \mathrm{CD} /$ camphor-IC-NF. Despite its lower encapsulation efficiency, the reason for the higher release amount of $\mathrm{HP} \beta \mathrm{CD} /$ camphor-IC-NF compared to $\mathrm{HP} \gamma \mathrm{CD} /$ camphor-IC-NF might be originated from the slightly weaker interaction of $\mathrm{HP} \beta C D$ and camphor, which was revealed by the phase solubility and modeling studies. Moreover, when we consider the favorable allocation of camphor molecules inside the CD cavity demonstrated by the modeling study, camphor prefers to position at the edge of the wider rim of CD molecules in case of HP $\beta C D$ (Fig. 3a), which most probably leads to easier release of guest molecules from the cavity of HP $\beta C D$ compared to $\mathrm{HP} \gamma \mathrm{CD}$. On the contrary, camphor molecules prefer to locate at inner side of the narrow rim of $\mathrm{HP} \gamma \mathrm{CD}$, which might create a more stable interaction for camphor by the steric hindrance of hydroxypropyl moieties. The calculated higher encapsulation efficiency of $\mathrm{HP} \gamma \mathrm{CD} /$ camphor-IC-NF $(\sim$ 1.00:0.90) than $\mathrm{HP} \beta \mathrm{CD} /$ camphor-IC-NF ( 1.00:0.65) might be also based on this positioning differences of these two $C D$ types, such that weaker interaction of $\mathrm{HP} \beta \mathrm{CD} / \mathrm{cam}$ phor-IC might allow easier evaporation of camphor during electrospinning and storage.

\section{Conclusion}

Inclusion complexes (ICs) from two kinds of CD derivatives ( $\mathrm{HP} \beta \mathrm{CD}$ and $\mathrm{HP} \gamma \mathrm{CD}$ ) and camphor which is known for its volatile and hydrophobic nature were formed in highly concentrated aqueous solutions for the electrospinning of nanofibers (HPßCD/camphor-IC-NF and HP $\gamma \mathrm{CD} /$ camphor-IC$\mathrm{NF}$ ). The phase solubility studies indicated the watersolubility increase of camphor with $C D$, and the 1:1 molar ratio was observed for these inclusion complexes (HP $\beta C D$ /camphor-IC and $\mathrm{HP} \gamma \mathrm{CD}$ /camphorIC). In addition, the stability constant calculated for $\mathrm{HP} \gamma \mathrm{CD} /$ camphor-IC was higher than $\mathrm{HP} \beta \mathrm{CD} / \mathrm{cam}-$ phor-IC, suggesting that $\mathrm{HP} \gamma \mathrm{CD}$ can form relatively more stable inclusion complexes with camphor when compared to HPßCD. Computational modeling 
studies also showed that the interaction between camphor and $\mathrm{HP} \gamma \mathrm{CD}$ is slightly stronger than the interaction with HP $\beta C D$ due to the better allocation of camphor in $\mathrm{HP} \gamma \mathrm{CD}$, which leads to more favorable interaction compare to HP $\beta C D$. In addition, computational modeling study also indicated that the preferential orientation of camphor is variable depending on the $\mathrm{CD}$ types. After electrospinning of these $\mathrm{CD} /$ camphor-IC solutions without using any polymer template, self-standing and flexible nanofibrous webs of $\mathrm{HP} \beta \mathrm{CD} /$ camphor-IC-NF and $\mathrm{HP} \gamma \mathrm{CD} /$ camphor-IC-NF were produced. These CD/camphor-ICNF webs have shown fast-dissolving characteristic, and camphor was become readily water soluble. Even camphor is quite a volatile molecule, the initial molar ratio of CD:camphor (1:1) in CD/camphor-IC solutions was significantly preserved after electrospinning of CD/camphor-IC-NF samples. The CD:camphor molar ratio was determined from ${ }^{1} \mathrm{H}-\mathrm{NMR}$ studies, and it was found to be $\sim 1.00: 0.65$ and $\sim$ 1.00:0.90 for HPßCD/camphor-IC-NF and $\mathrm{HP} \gamma \mathrm{CD} /$ camphor-IC-NF, respectively. The DSC, $X R D$, and FTIR studies confirmed that the inclusion complexation state was present between $\mathrm{CD}$ and camphor after electrospinning of $\mathrm{HP} \beta \mathrm{CD} /$ camphorIC-NF and $\mathrm{HP} \gamma \mathrm{CD} /$ camphor-IC-NF nanofibrous webs. TGA studies revealed the improvement in the thermal stability of camphor when it is included in the cavity of $\mathrm{CDs}$ in $\mathrm{CD} /$ camphor-IC-NFs. The release of camphor from $\mathrm{CD} /$ camphor-IC-NFs was measured at 37 and $75^{\circ} \mathrm{C}$, and less amount of camphor was released from $\mathrm{HP} \gamma \mathrm{CD} /$ camphor-IC-NF possibly due to the stronger interaction between $\mathrm{HP} \gamma \mathrm{CD}$ and camphor as suggested by the phase solubility results and computational modeling studies.

\section{Acknowledgements}

Dr. A. Celebioglu thanks TUBITAK-BIDEB for the Ph.D. scholarship. Dr. Z. Aytac thanks TUBITAKBIDEB and TUBITAK (Project \# 213M185) for the Ph.D. scholarship.

Funding Dr. Uyar acknowledges the Scientific and Technological Research Council of Turkey (TUBITAK)_Turkey (Project \# 213M185) for funding this research. Dr. Uyar and Dr. Durgun also acknowledge the partial support from the Turkish Academy of
Sciences-Outstanding Young Scientists Award Program (TUBA-GEBIP)-Turkey. The computational resources are provided by TUBITAK ULAKBIM, High Performance and Grid Computing Center (TRGrid e-Infrastructure), and the National Center for High Performance Computing of Turkey (UHeM) under Grant No. 5003622015.

Electronic supplementary material: The online version of this article (https://doi.org/10.1007/ s10853-017-1918-4) contains supplementary material, which is available to authorized users.

\section{References}

[1] Bakkali F, Averbeck S, Averbeck D, Idaomar M (2008) Biological effects of essential oils-a review. Food Chem Toxicol 46(2):446-475

[2] El Asbahani A, Miladi K, Badri W, Sala M, Addi EA, Casabianca H, El Mousadik A, Hartmann D, Jilale DA, Renaud FNR, Elaissari A (2015) Essential oils: from extraction to encapsulation. Int J Pharm 483(1):220-243

[3] Uyar T, Kny E (eds) (2017) Electrospun materials for tissue engineering and biomedical applications: research, design and commercialization. Woodhead Publishing, Cambridge

[4] Wen P, Wen Y, Zong M-H, Linhardt RJ, Wu H (2017) Encapsulation of bioactive compound in electrospun fibers and its potential application. J Agric Food Chem 65:9161-9179

[5] Wendorff JH, Agarwal S, Greiner A (2012) Electrospinning: materials, processing, and applications. Wiley, Weinheim

[6] Bilensoy E (ed) (2011) Cyclodextrins in pharmaceutics, cosmetics, and biomedicine: current and future industrial applications. Wiley, Hoboken, New Jersey

[7] Del Valle EM (2004) Cyclodextrins and their uses: a review. Process Biochem 39(9):1033-1046

[8] Szejtli J (1998) Introduction and general overview of cyclodextrin chemistry. Chem Rev 98(5):1743-1754

[9] Aytac Z, Dogan SY, Tekinay T, Uyar T (2014) Release and antibacterial activity of allyl isothiocyanate/ $\beta$-cyclodextrin complex encapsulated in electrospun nanofibers. Colloids Surf B 120:125-131

[10] Aytac Z, Ipek S, Durgun E, Tekinay T, Uyar T (2017) Antibacterial electrospun zein nanofibrous web encapsulating thymol/cyclodextrin-inclusion complex for food packaging. Food Chem 233:117-124

[11] Uyar T, Hacaloglu J, Besenbacher F (2009) Electrospun polystyrene fibers containing high temperature stable volatile 
fragrance/flavor facilitated by cyclodextrin inclusion complexes. React Funct Polym 69(3):145-150

[12] Kayaci F, Uyar T (2012) Encapsulation of vanillin/cyclodextrin inclusion complex in electrospun polyvinyl alcohol (PVA) nanowebs: prolonged shelf-life and high temperature stability of vanillin. Food Chem 133(3):641-649

[13] Celebioglu A, Uyar T (2011) Electrospinning of polymerfree nanofibers from cyclodextrin inclusion complexes. Langmuir 27(10):6219-6226

[14] Celebioglu A, Umu OC, Tekinay T, Uyar T (2014) Antibacterial electrospun nanofibers from triclosan/cyclodextrin inclusion complexes. Colloids Surf B 116:612-619

[15] Aytac Z, Yildiz ZI, Kayaci-Senirmak F, San Keskin NO, Tekinay T, Uyar T (2016) Electrospinning of polymer-free cyclodextrin/geraniol-inclusion complex nanofibers: enhanced shelf-life of geraniol with antibacterial and antioxidant properties. RSC Adv 6(52):46089-46099

[16] Celebioglu A, Kayaci-Senirmak F, Ipek S, Durgun E, Uyar T (2016) Polymer-free nanofibers from vanillin/cyclodextrin inclusion complexes: high thermal stability, enhanced solubility and antioxidant property. Food Funct 7(7):3141-3153

[17] Aytac Z, Yildiz ZI, Kayaci-Senirmak F, San Keskin NO, Kusku SI, Durgun E, Tekinay T, Uyar T (2016) Fast-dissolving, prolonged release, and antibacterial cyclodextrin/ limonene-inclusion complex nanofibrous webs via polymerfree electrospinning. J Agric Food Chem 64(39):7325-7334

[18] Aytac Z, Yildiz ZI, Kayaci-Senirmak F, Tekinay T, Uyar T (2017) Electrospinning of cyclodextrin/linalool-inclusion complex nanofibers: fast-dissolving nanofibrous web with prolonged release and antibacterial activity. Food Chem 231:192-201

[19] Celebioglu A, Uyar T (2017) Antioxidant vitamin E/cyclodextrin inclusion complex electrospun nanofibers: enhanced water-solubility, prolonged shelf-life and photostability of vitamin E. J Agric Food Chem 65(26):5404-5412

[20] Celebioglu A, Yildiz ZI, Uyar T (2017) Electrospun nanofibers from cyclodextrin inclusion complexes with cineole and p-cymene: enhanced water solubility and thermal stability. Int J Food Sci Technol. https://doi.org/10.1111/ijfs. 13564

[21] Celebioglu A, Uyar T (2010) Cyclodextrin nanofibers by electrospinning. Chem Commun 46(37):6903-6905

[22] Celebioglu A, Uyar T (2012) Electrospinning of nanofibers from non-polymeric systems: polymer-free nanofibers from cyclodextrin derivatives. Nanoscale 4(2):621-631

[23] Chang CP, Leung TK, Lin SM, Hsu CC (2006) Release properties on gelatin-gum arabic microcapsules containing camphor oil with added polystyrene. Colloids Surf B 50(2):136-140

[24] Higuchi TK, Connors A (1965) Phase-solubility techniques. Adv Anal Chem Instrum 4:117-212

[25] Yalkowsky SH, He Y, Jain P (2016) Handbook of aqueous solubility data. CRC Press, Boca Raton

[26] Kohn W, Sham LJ (1965) Self-consistent equations including exchange and correlation effects. Phys Rev 140(4A):A1133-A1138

[27] Hohenberg P, Kohn W (1964) Inhomogeneous electron gas. Phys Rev 136(3B):B864-B871

[28] Kresse G, Furthmüller J (1996) Efficient iterative schemes for ab initio total-energy calculations using a plane-wave basis set. Phys Rev B 54(16):11169-11186

[29] Kresse G, Furthmüller J (1996) Efficiency of ab initio total energy calculations for metals and semiconductors using a plane-wave basis set. Comput Mater Sci 6(1):15-50

[30] Perdew JP, Burke K, Ernzerhof M (1996) Generalized gradient approximation made simple. Phys Rev Lett 77(18):3865-3868

[31] Grimme S (2006) Semiempirical GGA-type density functional constructed with a long-range dispersion correction. J Comput Chem 27(15):1787-1799

[32] Blöchl PE (1994) Projector augmented-wave method. Phys Rev B 50(24):17953-17979

[33] Kresse G, Joubert D (1999) From ultrasoft pseudopotentials to the projector augmented-wave method. Phys Rev B 59(3):1758-1775

[34] Mathew K, Sundararaman R, Letchworth-Weaver K, Arias TA, Hennig RG (2014) Implicit solvation model for densityfunctional study of nanocrystal surfaces and reaction pathways. J Chem Phys 140(8):084106-084108

[35] Aleem O, Kuchekar B, Pore Y, Late S (2008) Effect of $\beta$ cyclodextrin and hydroxypropyl $\beta$-cyclodextrin complexation on physicochemical properties and antimicrobial activity of cefdinir. J Pharm Biomed Anal 47(3):535-540

[36] Pralhad T, Rajendrakumar K (2004) Study of freeze-dried quercetin-cyclodextrin binary systems by DSC, FT-IR, X-ray diffraction and SEM analysis. J Pharm Biomed Anal 34(2):333-339

[37] Tanaka M, Matsuda H, Sumiyoshi H, Arima H, Hirayama F, Uekama K, Tsuchiya S (1996) 2-Hydroxypropylated cyclodextrins as a sustained-release carrier for fragrance materials. Chem Pharm Bull 44(2):416-420

[38] Ciobanu A, Landy D, Fourmentin S (2013) Complexation efficiency of cyclodextrins for volatile flavor compounds. Food Res Int 53(1):110-114

[39] Kokkinou A, Tsorteki F, Karpusas M, Papakyriakou A, Bethanis K, Mentzafos D (2010) Study of the inclusion of the (R)-and (S)-camphor enantiomers in $\alpha$-cyclodextrin by 
X-ray crystallography and molecular dynamics. Carbohyd Res 345(8):1034-1040

[40] Celebioglu A, Uyar T (2013) Electrospun gamma-cyclodextrin $(\gamma-\mathrm{CD})$ nanofibers for the entrapment of volatile organic compounds. RSC Adv 3(45):22891-22895

[41] Celebioglu A, Uyar T (2013) Electrospinning of nanofibers from non-polymeric systems: electrospun nanofibers from native cyclodextrins. J Colloid Interface Sci 404:1-7

[42] Shenoy SL, Bates WD, Frisch HL, Wnek GE (2005) Role of chain entanglements on fiber formation during electrospinning of polymer solutions: good solvent, non-specific polymer-polymer interaction limit. Polymer 46(10):3372-3384
[43] Uyar T, Besenbacher F (2008) Electrospinning of uniform polystyrene fibers: the effect of solvent conductivity. Polymer 49(24):5336-5343

[44] Aytac Z, Sen HS, Durgun E, Uyar T (2015) Sulfisoxazole/cyclodextrin inclusion complex incorporated in electrospun hydroxypropyl cellulose nanofibers as drug delivery system. Colloids Surf B 128:331-338

[45] Wang C, Wang H, Liu Y (2016) Purification of Pb(II) ions from aqueous solution by camphor leaf modified with succinic anhydride. Colloids Surf A 509:80-85

[46] Hu CY, Chen M, Wang ZW (2012) Release of thymol, cinnamaldehyde and vanillin from soy protein isolate films into olive oil. Packag Technol Sci 25(2):97-106 